\title{
Optimization of Exothermic, Foaming, and Mechanical Properties of Modified Polyurethane as Filling Material for Goaf Sealing Wall
}

\author{
Jianjun Shen, ${ }^{1,2,3}$ Baihui Ren, ${ }^{1}$ Weitao Liu $\left(\mathbb{D},{ }^{3,4}\right.$ Chuanpeng Gao, ${ }^{1}$ Yingying Hu, ${ }^{2}$ \\ and Qing $\mathbf{C a o}^{2}$ \\ ${ }^{1}$ College of Safety and Environmental Engineering, Shandong University of Science and Technology, Qingdao 266590, China \\ ${ }^{2}$ College of Chemical Engineering and Safety, Binzhou University, Binzhou 256600, China \\ ${ }^{3}$ Key Laboratory of Mining Disaster Prevention and Control, Shandong University of Science and Technology, \\ Qingdao 266590, China \\ ${ }^{4}$ College of Energy and Mining Engineering, Shandong University of Science and Technology, Qingdao 266590, China
}

Correspondence should be addressed to Weitao Liu; liuwt172@163.com

Received 15 August 2020; Accepted 3 December 2020; Published 23 December 2020

Academic Editor: Victor M. Castaño

Copyright $\odot 2020$ Jianjun Shen et al. This is an open access article distributed under the Creative Commons Attribution License, which permits unrestricted use, distribution, and reproduction in any medium, provided the original work is properly cited.

\begin{abstract}
Goaf sealing wall is set in the roadway close to the stop line of working face in an underground coal mine. However, the sealing wall is prone to crack or fracture under serious mining stress, resulting in water and air leakage from goaf. In this study, the combination of polymethylene polyphenyl polyisocyanate (PAPI) and methylene diphenyl diisocyanate (MDI) as component A and polyether polyols, catalysts, surfactants, chain extenders, and plasticizers as component B were investigated to optimize the exothermic, foaming, and mechanical properties of modified polyurethane (PU) as the filling material for goaf sealing wall. Firstly, the reaction temperature of specimens with different contents of polyether polyols was monitored using a dynamic acquisition system; secondly, the effect of polyether polyols, catalysts, and surfactants on foaming property was studied; then, uniaxial compression tests were developed to obtain compressive behavior; finally, the microstructure after uniaxial compression was observed by using a scanning electron microscope (SEM). The results indicate that the pure chemical slurry is superior to the combination of chemical slurry and sand in compressive strength and deformation behavior. The optimal mass ratio of polyether triols, polyether tetraols, catalysts, surfactants, chain extenders, and plasticizers is $11: 9: 1.0: 0.5: 1.2: 6$ in component $B$ due to the maximum reaction temperature of $121.4^{\circ} \mathrm{C}$, the expansion ratio of 2.6, and the compressive strength of $7.97 \mathrm{MPa}$ at the strain of $10 \%$ in this study. The research provides a solution for the construction of the sealing wall, which is of great significance to safety production in an underground coal mine.
\end{abstract}

\section{Introduction}

In recent years, polymer materials have developed in the field of engineering, considering their foaming and mechanical properties, particularly in reservoir dam $[1,2]$, traffic tunnel [3, 4], underground coal mine, and other underground construction [5, 6]. Polymer materials are mainly used for reinforcing coal and rock mass as grouting material, plugging water seepage as grouting material, sealing caving cavity or abandoned roadway as filling material, and preventing air leakage as spraying material in an underground coal mine [7-10]. Polymer materials used for grouting, filling, and spraying in underground coal mines are polyurethane (PU) [11], epoxy resin (EP) [12], acrylamide (AM) [13], methyl methacrylate (MMA) [14], and acrylates (AAS) [15]. In addition, some organic-inorganic composite materials [16-18] and modified materials [19-21] are also under continuous development. Among these polymer materials, $\mathrm{PU}$ materials have been widely used in an underground coal mine. The ideal PU materials should have the following characteristics: wide source of raw materials, low reaction temperature, terrific flame retardancy, high 
expansion ratio, excellent mechanical properties, good flowability, less toxicity, and harmless.

Under different conditions, there are different requirements for the properties of PU materials [22-27]. As a filling material, the chemical slurry is injected into the caving cavity or enclosed space, which then expands into a sealing solid in a short time due to its outstanding foaming, mechanical properties, and high chemical reaction rate. When used as a filling body in the underground coal mine, PU materials are divided into $\mathrm{N}$-type and $P$-type according to their mechanical characteristics and performance. $N$-type is used for filling enclosed space that does not need to be loaded, such as gas drainage drilling space and upper and lower corners of coal mining face. $P$-type is used for filling enclosed space that needs to be loaded, such as caving cavity and sealing wall. Sealing wall is set in the roadway close to the stop line of the working face in order to prevent water and air leakage from goaf. However, gypsum sealing walls, brick sealing walls, and concrete sealing walls are prone to crack or fracture under mining stress, which leads to water and air leakage from goaf. Therefore, $P$-type PU filling materials suitable for the composite sealing wall were proposed in this study.

For a long time, great progress has been made in the application of new materials for sealing walls [28-30]. Among them, PU grouting materials have been widely used in coal mines due to their unique advantages of fast curing speed, high expansion rate, and excellent flexibility. Liu [31] investigated the influence of kaolin content on the performance of RPUKCF by modifying the surface of kaolin in the process of coal mining and adding it to the polyurethane matrix, which can be used in underground coal mines to prevent leakage and plug leakage. By adding TCEP to the PU material, Cheng and Shen [32] successfully prepared a flame-retardant PU filling material that can be used in underground coal mines. Luo et al. [33], in view of the limitations in the application of the current mine closed filling materials, prepared a new type of hydrogel filling material by a two-solution mixing method, which provided a new method for underground mine disaster management.

The key point is formula optimization considering exothermic, foaming, and mechanical properties. In detail, the filling materials need not only expansion ratio but also certain compressive strength, and most importantly, large deformation before crack or fracture. In addition, the maximum reaction temperature should not exceed the national standard. However, there are few reports on the relationship between formula and expansion ratio, reaction temperature, compressive strength, and deformation of $\mathrm{PU}$ filling materials. Moreover, in the selection of filling-body, three situations are considered: the first is pure chemical slurry, the second is the combination of coarse sand and chemical slurry, and the third is the combination of fine sand and chemical slurry. Which type has the best effect needs to be further explored and discussed. Thus, it is very important to study the optimal formula of PU filling materials which take into account the exothermic, foaming, and mechanical properties.

In the construction of the sealing wall, the expansion effect of PU grouting material can tightly combine the sealing wall with the periphery of the roadway, thus avoiding the problem that the filling material cannot completely fill the sealed space and leaves an air guide channel around the sealing wall due to the existence of uneven surface of the roadway or dead corners of filling. In roadway grouting, PU grouting material can expand the fissures when solidified, which plays a good role in blocking the air-conducting fissures in the broken zone. Therefore, PU grouting material can well satisfy the requirements of bearing capacity, deformation capacity, and airtightness of goaf sealing wall and provides effective support for safe production in the coal mine.

In view of the above background, in this study, the combination of polymethylene polyphenyl polyisocyanate (PAPI) and methylene diphenyl diisocyanate (MDI) as component A and polyether polyols, catalysts, surfactants, chain extenders, and plasticizers as component B were investigated to optimize the exothermic, foaming, and mechanical properties of modified polyurethane (PU) as filling materials for goaf sealing wall. Dynamic acquisition system and thermocouple sensor, electrohydraulic servo control pressure testing machine, and scanning electron microscope (SEM) were used to characterize the above properties. After that, the optimal formula was determined to construct sealing wall as filling materials. The results are of great significance for safe production in underground coal mines.

\section{Materials and Methods}

2.1. Materials. The PU materials are composed of isocyanates, polyols, catalysts, surfactants, plasticizers, crosslinkers, chain extenders, flame retardants, and smoke suppressants. The above materials are divided into component $\mathrm{A}$ and component $\mathrm{B}$; among them, isocyanates belong to component $\mathrm{A}$ and the rest belong to component $\mathrm{B}$. In general, toluene diisocyanate (TDI) and methylene diphenyl diisocyanate (MDI), or a combination of them, are most widely used in component A. However, low-toxic polymethylene polyphenyl polyisocyanate (PAPI) was rarely mentioned in the past application. In this study, the combination of PAPI and MDI was adopted in component A, and the ratio of them was $4: 1$. Component $\mathrm{B}$ included polyether polyols, catalysts, surfactants, chain extenders, and plasticizers. The types of the above materials are listed in Table 1.

The exothermic, foaming, and mechanical properties were affected by a different proportion of raw materials in component B. Tables 2 and 3 show the experimental scheme to study the effects of polyether polyols (polyether triols as a and polyether tetraols as b), catalysts, and surfactants in component $\mathrm{B}$ on the above properties.

\subsection{Preparation of Filling Materials and Standard Specimens.}

The preparation process of standard specimens is divided into four steps, as shown in Figure 1.

(i) Preparation of component A: the mass of PAPI was $18.0-25.0 \mathrm{~g}$, the mass of MDI was 3.0-6.0 g, and the mass ratio of the two was $4: 1$. 
TABLE 1: Type of raw materials.

\begin{tabular}{lcc}
\hline Raw materials & Type & Specification \\
\hline PAPI & PM-100 & Chemically pure (CP) \\
MDI (MDI) & PMM-20 & Chemically pure (CP) \\
Polyether triols & GP-306 & Chemically pure (CP) \\
Polyether tetraols & HK-4110G & Chemically pure (CP) \\
Catalysts & A33 & Chemically pure (CP) \\
Surfactants & BL-8468 & Chemically pure (CP) \\
Chain extenders & DEG & Analytical reagent (AR) \\
Plasticizers & DOP & Analytical reagent (AR) \\
\hline
\end{tabular}

TABLE 2: Orthogonal test scheme of three factors and four levels (L16).

\begin{tabular}{lccc}
\hline \multirow{3}{*}{ Level } & \multicolumn{3}{c}{ Factors } \\
& Polyether polyols a:b & Catalyst A33 & Surfactant BL-8468 \\
\hline 1 & $9: 11$ & 0.5 & 0.5 \\
2 & $10: 10$ & 0.8 & 0.6 \\
3 & $11: 9$ & 1.0 & 0.7 \\
4 & $8: 12$ & 1.2 & 0.8 \\
\hline
\end{tabular}

(ii) Preparation of component B: the mass of polyether polyols was $15.0-25.0 \mathrm{~g}$, the mass of catalysts was $0.5-1.2 \mathrm{~g}$, and the mass of surfactants was $0.5-0.8 \mathrm{~g}$. In addition, the mass of chain extenders and plasticizers was fixed, which were $1.2 \mathrm{~g}$ and $6.0 \mathrm{~g}$, respectively.

(iii) Components $\mathrm{A}$ and $\mathrm{B}$ were prepared according to the mass ratio of $1: 1$. When used, components $\mathrm{A}$ and $\mathrm{B}$ were mixed and stirred evenly.

(iv) The mixed chemical slurry was quickly injected into the mold, and then standard specimens were prepared after the reaction.

Through the above process, the specimens of pure chemical slurry (PCS), specimens containing coarse sand (CCS), and specimens containing fine sand (CFS) were prepared.

2.3. Reaction Temperature Monitoring. The reaction temperature has an important relationship with the composition, particularly the proportion of polyether polyols. Therefore, four groups of specimens with different mass ratios of polyether polyols were considered. Table 3 illustrates the mass ratio of polyether triols and polyether tetraols from Group I to Group IV, which were 9:11, 10:10, 11:9, and $8: 12$, respectively. After the mixture of components $\mathrm{A}$ and $\mathrm{B}$, the polymerization reaction mainly occurred. In order to test the reaction temperature, the dynamic acquisition system and thermocouple sensor were used, as shown in Figure 2(a).

2.4. Expansion Ratio Measuring. The foaming property could be expressed by the expansion ratio. Under the standard experimental conditions, the consolidated specimen was slowly put into the $2000 \mathrm{ml}$ beaker full of water; after that, the volume of the discharged water is the volume of the curing specimen. The expansion ratio is expressed by $F$, and the value is the ratio of the volume after reaction to the volume before reaction.

2.5. Mechanical Property Testing. Referring to JC/T 20412010 Polyurethane Grouting Material, an industrial standard of building materials of the People's Republic of China, the specimens were made in a standard cylinder of $50 \mathrm{~mm}$ in diameter and $100 \mathrm{~mm}$ in length. After the specimens were cured, the mold was removed, and then the surface of the specimens was polished and smoothed with sandpaper. Uniaxial compression tests were conducted on standard specimens using an electrohydraulic servo control pressure testing machine, and displacement loading was adopted with the rate of $0.01 \mathrm{~mm} / \mathrm{s}$, as shown in Figure 2(b).

2.6. Microstructure Observing. In view of the porosity characteristics on the microscale of PU materials, SEM was used to observe and record the micromorphology of materials with typical density under vacuum, as shown in Figure 2(c). In order to obtain SEM results, the specimens were cut into thin slices of about $2.0 \mathrm{~mm}$ in thickness, and the thin slices were broken off to obtain a brittle fracture surface. Before testing, a metal film was plated on the nonconductive section of the target to enhance the conductivity and improve the image clarity and resolution.

\section{Results}

3.1. Physical and Chemical Properties. The main physical and chemical properties of component $\mathrm{A}$, component $\mathrm{B}$, and their mixture are presented in Table 4.

3.2. Reaction Temperature. In this experiment, the reaction temperature with the corresponding reaction time was recorded. The relationship of reaction temperature and time is shown in Figure 3, and Figure 3(b) is the enlarged part of Figure 3(a).

The data suggest that the maximum reaction temperature of specimens in four groups were quite different, which fluctuates within the range of $110^{\circ} \mathrm{C}$ to $138^{\circ} \mathrm{C}$. The materials reached the maximum temperature within 6 minutes, but the heat dissipation was slow, and it has taken about 2 hours to return to room temperature. According to the National Safety Production Industry standards, the reaction temperature of $\mathrm{PU}$ materials used in underground coal mines should be lower than $140^{\circ} \mathrm{C}$; therefore, the above materials conformed to the national standards.

3.3. Expansion Ratio. Table 5 shows that the expansion ratio of 16 kinds of specimens ranging from 1.3 to 3.5. The data suggest that, among the three experimental factors, the range of surfactant was the largest, which was 1.100 , so the surfactant has the greatest effect on the foaming property.

The results of the analysis of variance in Table 6 showed the significance of the influence of each factor on the expansion ratio, which was consistent with the results of the 
TABle 3: Proportioning schemes of component B.

\begin{tabular}{|c|c|c|c|c|c|c|}
\hline \multirow{2}{*}{ Group of specimens } & \multirow{2}{*}{ Number of specimens } & \multicolumn{5}{|c|}{ Mass ratio of raw materials in component $B$} \\
\hline & & Polyether polyols $\mathrm{a}: \mathrm{b}$ & Catalysts & Surfactants & Chain extenders & Plasticizers \\
\hline \multirow{4}{*}{ Group I } & 1 & $9: 11$ & 0.5 & 0.5 & \multirow{8}{*}{1.2} & \multirow{8}{*}{6} \\
\hline & 2 & $9: 11$ & 0.8 & 0.6 & & \\
\hline & 3 & $9: 11$ & 1.0 & 0.7 & & \\
\hline & 4 & $9: 11$ & 1.2 & 0.8 & & \\
\hline \multirow{4}{*}{ Group II } & 5 & $10: 10$ & 0.5 & 0.6 & & \\
\hline & 6 & $10: 10$ & 0.8 & 0.5 & & \\
\hline & 7 & $10: 10$ & 1.0 & 0.8 & & \\
\hline & 8 & $10: 10$ & 1.2 & 0.7 & & \\
\hline \multirow{4}{*}{ Group III } & 9 & $11: 9$ & 0.5 & 0.7 & & \\
\hline & 10 & $11: 9$ & 0.8 & 0.8 & & \\
\hline & 11 & $11: 9$ & 1.0 & 0.5 & & \\
\hline & 12 & $11: 9$ & 1.2 & 0.6 & & \\
\hline \multirow{4}{*}{ Group IV } & 13 & $8: 12$ & 0.5 & 0.8 & & \\
\hline & 14 & $8: 12$ & 0.8 & 0.7 & & \\
\hline & 15 & $8: 12$ & 1.0 & 0.6 & & \\
\hline & 16 & $8: 12$ & 1.2 & 0.5 & & \\
\hline
\end{tabular}

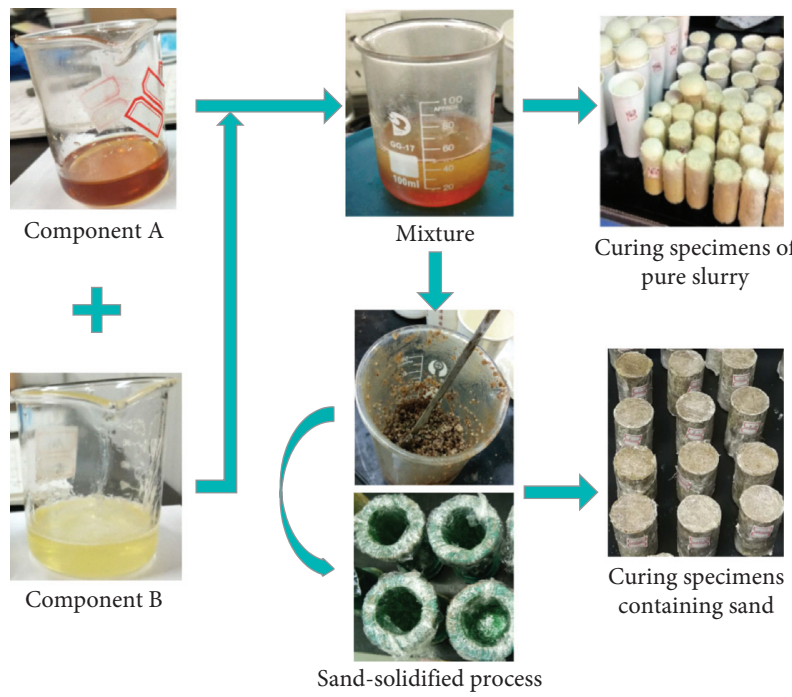

Figure 1: Preparation process of filling materials and standard specimens.

range analysis. The surfactant had the largest $F$ value, which had a significant influence on the expansion ratio. In addition, the order of influence of each factor on the expansion ratio was the same, that is, surfactant $>$ polyether polyols a : b > catalyst, which showed that the surfactant was the most important factor affecting expansion ratio.

This was because the surfactant has the functions of emulsifying foam materials, stabilizing foam, and adjusting bubble cells. The adsorption and directional arrangement of surfactants were the main reasons for foam formation. By increasing the miscibility of each component, the gel tension of foam cells was balanced, and the cell wall had elasticity, so as to retain gas and prevent foam collapse. Proper amount of the surfactant can improve the expansion ratio, and the uniform cell structure produced can improve the compressive strength of the filling body. As can be seen from Table 5, when the dosage of the surfactant was 0.5 , the foaming volume was relatively large. In addition, as can be seen from Figures 4(a)-4(c), the cell structure was dense and evenly distributed and had a stable structural morphology.

\subsection{Mechanical Properties}

3.4.1. Deformation Characteristics under Uniaxial Compression. As shown in Figure 5, during the initial period of PCS under uniaxial compression, the curves rose relatively fast and then gradually tended to be gentle. The compressive response of the specimens had four stages: Stage I, Stage II, Stage III, and Stage IV. The corresponding compressive strains were less than $3 \%$, $3 \% \sim 10 \%, 10 \% \sim 35 \%$, and greater than $35 \%$, respectively. Stage I was the elastic stage, and the compressive strength increased rapidly. Stage II to stage IV were the plastic stage, at which the compressive strength increased gently and produced irrecoverable deformation. During the plastic stage, the cellulars of PCS were squeezed as the load increasing; as a result, the specimens continued to produce compression deformation. This gradually dense structure made the material resistant to compression.

As shown in Figure 6, the stress-strain curves of CCS and CFS under uniaxial compression rose gently in the initial state and then dropped sharply after reaching the ultimate compressive strength, which were caused by splitting failure. These curves were also divided into Stage I, Stage II, Stage III, and Stage IV, namely, compaction stage, elastic stage, yield stage, and failure stage. Due to the difference of mechanical properties, the corresponding compressive strain of each specimen in each stage is different. In the elastic stage, the strain of CCS developed relatively quickly due to its large pores. In the yield stage, the peak stress was taken as the characterization of compressive strength.

3.4.2. Uniaxial Compressive Strength. Due to the excellent toughness of PU materials, the specimens had not reached the failure load or maximum load when its relative deformation reached $40 \% \sim 50 \%$ during the compression test, as 


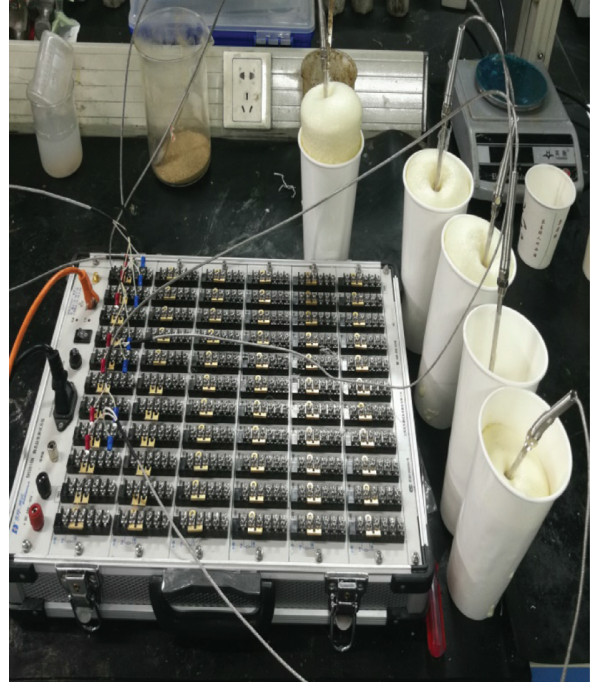

(a)

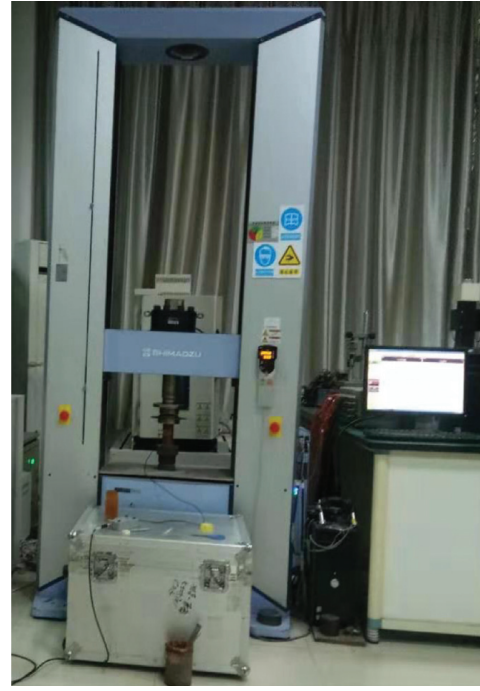

(b)

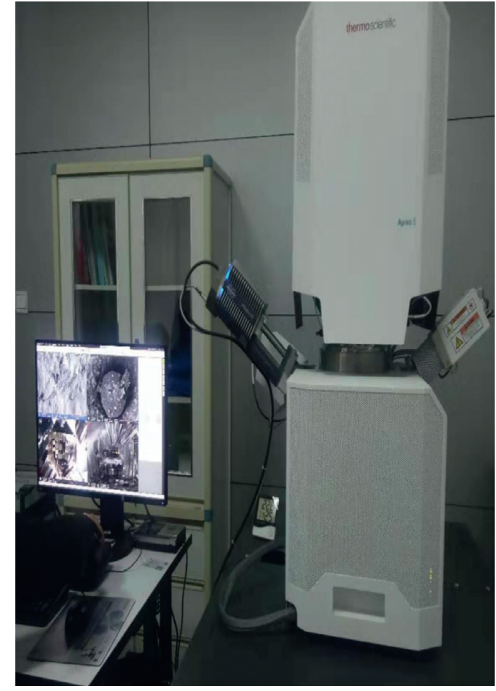

(c)

FIGURE 2: Experimental equipment: (a) dynamic acquisition system and thermocouple sensor; (b) electrohydraulic servo control pressure testing machine; (c) SEM.

TABle 4: Physical and chemical properties of component A, component B, and their mixture.

\begin{tabular}{lccc}
\hline Properties & Component A & Component B & Mixture by mass ratio \\
\hline Color & Brown & Opaque & Brown \\
Density $\left(\mathrm{g} \cdot \mathrm{cm}^{-3}\right)$ & 1.022 & 1.203 & $1.119-1.143$ \\
Gel time $(\mathrm{s})$ & & & $57-73$ \\
Curing time $(\mathrm{min})$ & & $9-13$ & $253-298$ \\
Viscosity @ 25 $\mathrm{C}(\mathrm{MPa} \cdot \mathrm{s})$ & & & 253 \\
\hline
\end{tabular}

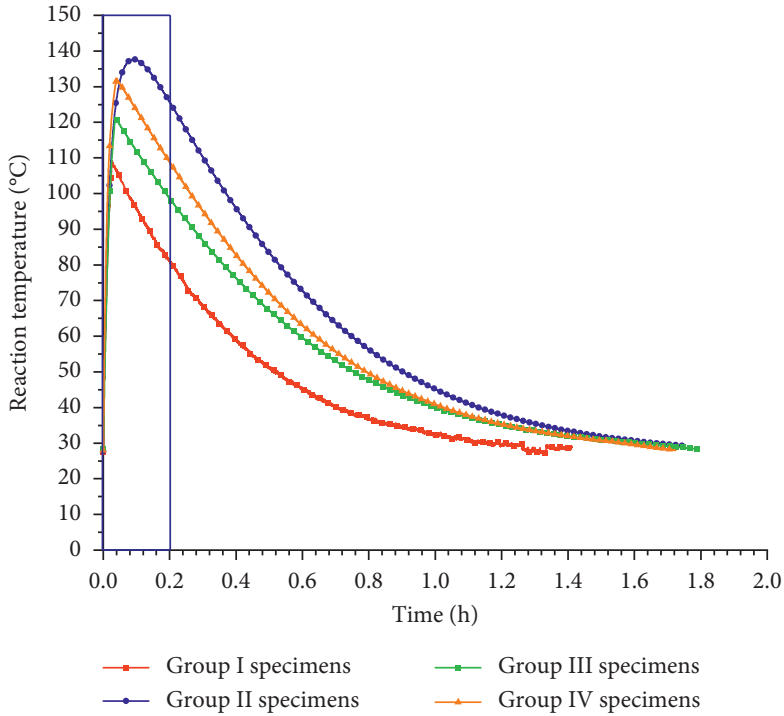

(a)

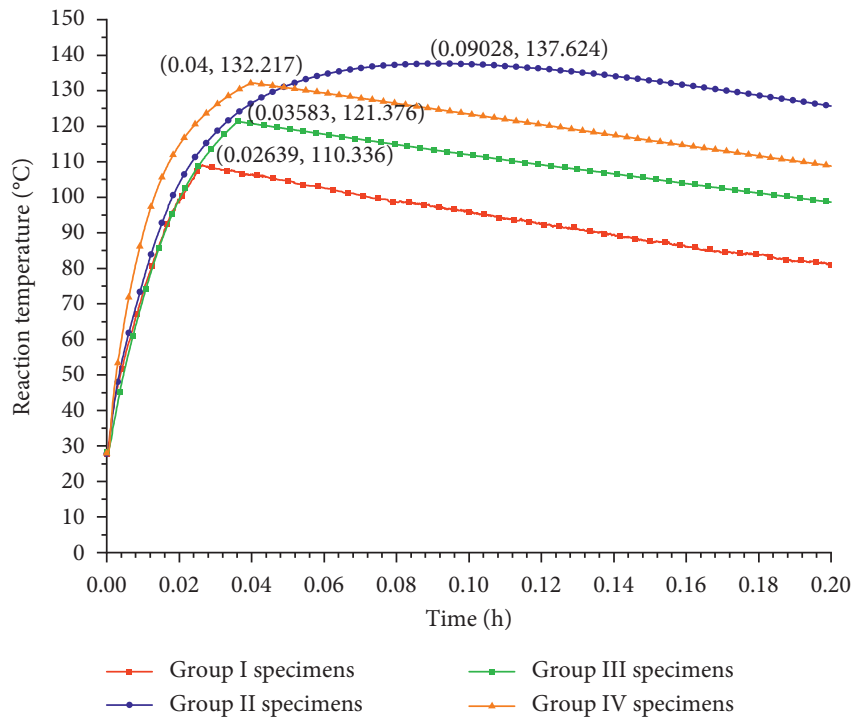

(b)

FIGURE 3: The relationship between reaction temperature and time: (a) overall curves of reaction temperature; among them, the mass ratio of polyether triols and polyether tetraols of group I to group IV was $9: 11,10: 10,11: 9$, and $8: 12$, respectively; (b) magnified curves of reaction temperature. 
TABLE 5: Results of expansion ratio.

\begin{tabular}{|c|c|c|c|c|c|}
\hline \multirow{2}{*}{ No. } & \multicolumn{4}{|c|}{$\begin{array}{ll}\text { Factors } \\
\end{array}$} & \multirow{2}{*}{$\begin{array}{c}\text { Index } \\
\text { Expansion ratio }\end{array}$} \\
\hline & & Mass ratio of polyether polyols $a: b$ & Catalyst A33 & Surfactant BL-8468 & \\
\hline 1 & & $9: 11$ & 0.5 & 0.5 & 2.9 \\
\hline 2 & & $9: 11$ & 0.8 & 0.6 & 3.5 \\
\hline 3 & & $9: 11$ & 1.0 & 0.7 & 1.5 \\
\hline 4 & & $9: 11$ & 1.2 & 0.8 & 1.3 \\
\hline 5 & & $10: 10$ & 0.5 & 0.6 & 2.0 \\
\hline 6 & & $10: 10$ & 0.8 & 0.5 & 2.2 \\
\hline 7 & & $10: 10$ & 1.0 & 0.8 & 1.3 \\
\hline 8 & & $10: 10$ & 1.2 & 0.7 & 1.4 \\
\hline 9 & & $11: 9$ & 0.5 & 0.7 & 2.1 \\
\hline 10 & & $11: 9$ & 0.8 & 0.8 & 1.9 \\
\hline 11 & & $11: 9$ & 1.0 & 0.5 & 2.6 \\
\hline 12 & & $11: 9$ & 1.2 & 0.6 & 2.6 \\
\hline 13 & & $8: 12$ & 0.5 & 0.8 & 1.5 \\
\hline 14 & & $8: 12$ & 0.8 & 0.7 & 2.1 \\
\hline 15 & & $8: 12$ & 1.0 & 0.6 & 2.2 \\
\hline 16 & & $8: 12$ & 1.2 & 0.5 & 3.3 \\
\hline \multirow{5}{*}{ Expansion ration } & $\overline{\mathrm{I}}_{j}$ & 2.300 & 2.275 & 2.750 & \\
\hline & $\overline{\mathrm{II}}_{j}$ & 1.725 & 2.400 & 2.300 & \\
\hline & $\overline{\mathrm{III}}_{i}$ & 2.025 & 1.900 & 1.750 & \\
\hline & $\overline{\mathrm{IV}}_{j}$ & 2.400 & 1.875 & 1.650 & \\
\hline & $\bar{R}_{j}^{j}$ & 0.675 & 0.525 & 1.100 & \\
\hline
\end{tabular}

TABLE 6: Variance analysis results of expansion ratio.

\begin{tabular}{|c|c|c|c|c|c|}
\hline Factors & Square of deviance & Degree of freedom & $F$ & $F \alpha=0.1$ & Significant level \\
\hline Polyether polyols $\mathrm{a}: \mathrm{b}$ & 0.965 & 3 & 0.488 & 2.810 & \\
\hline Catalyst A33 & 0.555 & 3 & 0.281 & 2.810 & \\
\hline Surfactant BL-8468 & 4.415 & 3 & 2.232 & 2.810 & Significant \\
\hline Error & 5.93 & & & & \\
\hline Sum & 11.865 & 9 & & & \\
\hline
\end{tabular}

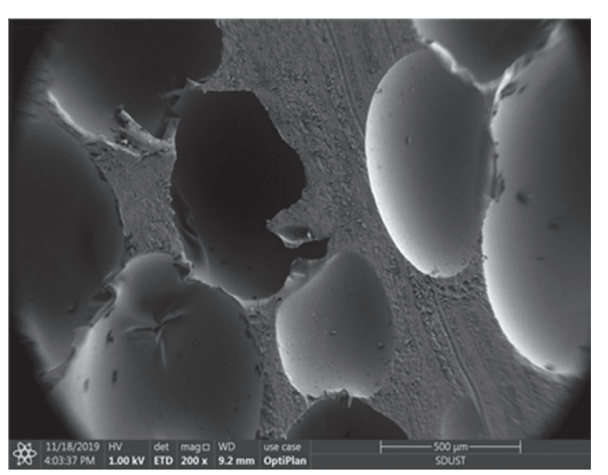

(a)

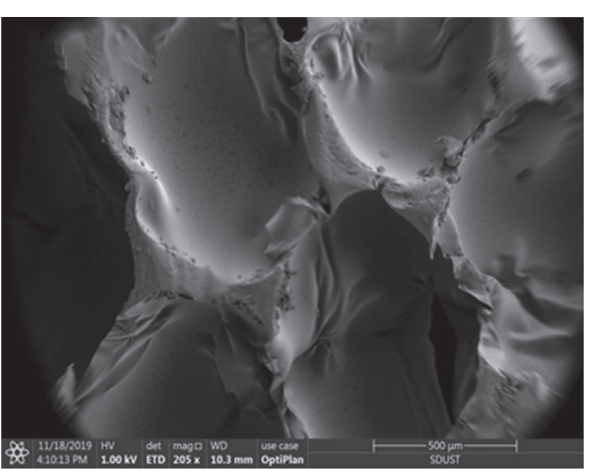

(b)

FIGURE 4: Continued. 


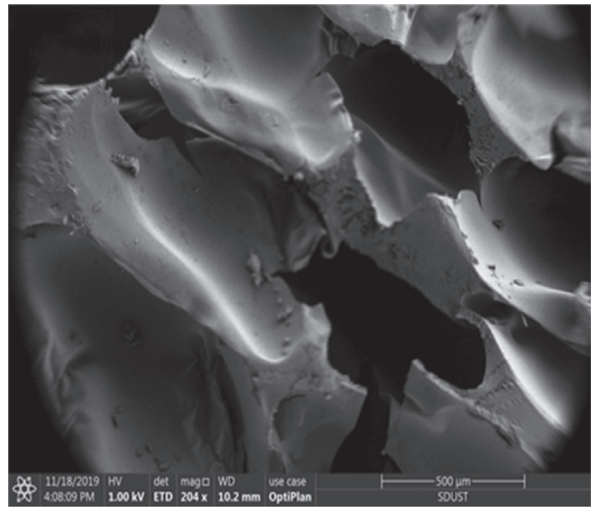

(c)

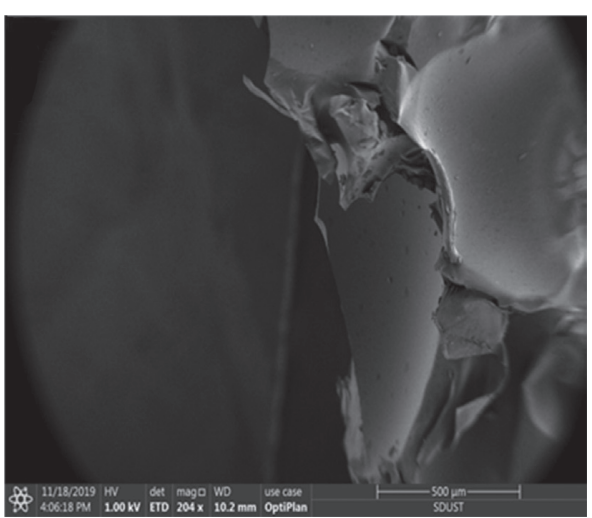

(d)

FIgURE 4: The SEM images of PCS after uniaxial compression experiment: (a) specimen 1 in group I with a surfactant ratio of 0.5 ; (b) specimen 5 in group II with a surfactant ratio of 0.6 ; (c) specimen 9 in group III with a surfactant ratio of 0.7 ; (d) specimen 13 in group IV with a surfactant ratio of 0.8 .

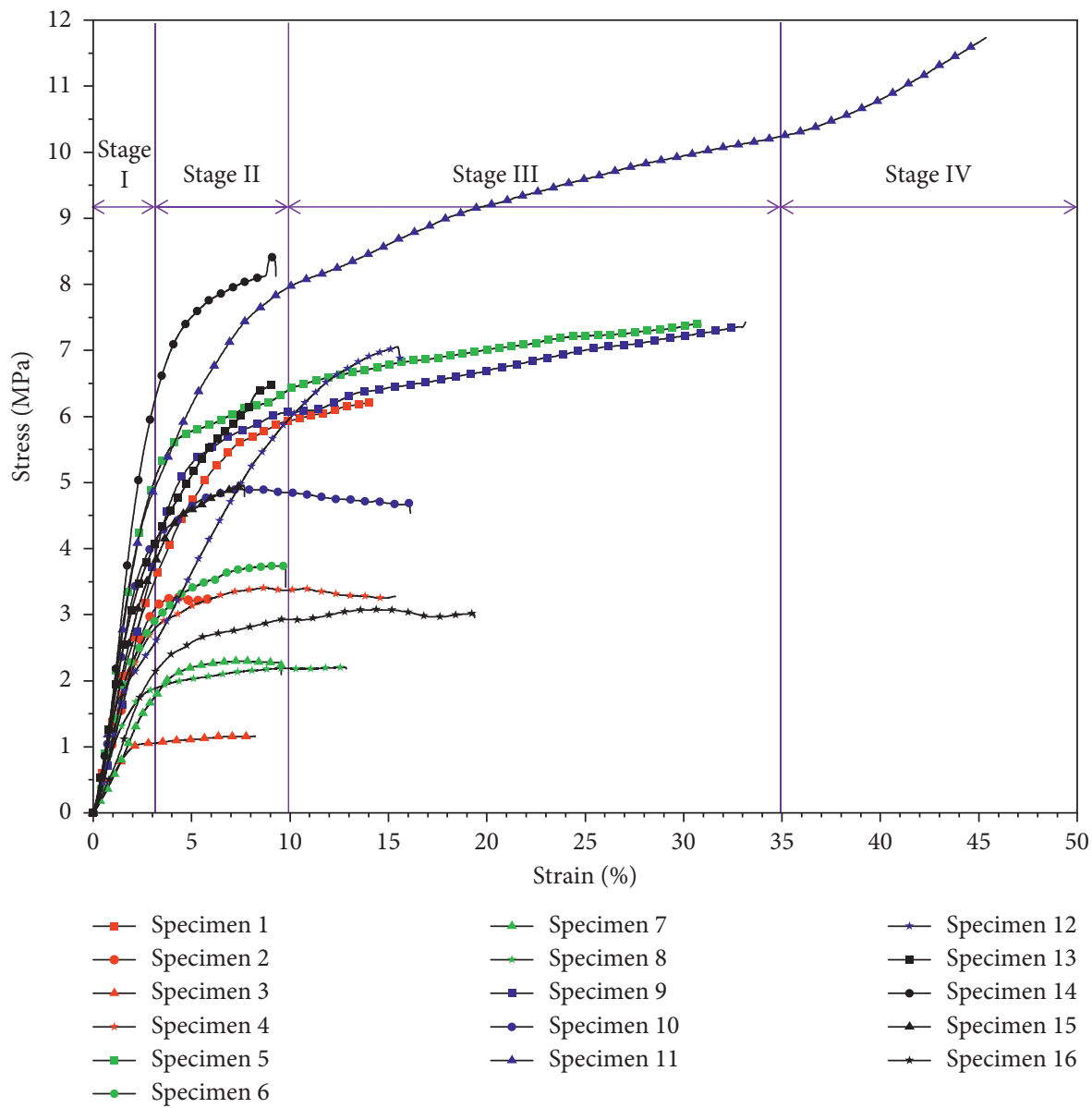

FIGURE 5: The stress-strain curves of PCS under uniaxial compression.

shown in Figure 6. The shape of the specimens changed greatly compared with that before the test, and the stressed area of the specimens was larger than that before the test, as shown in Figure 7. At this time, there is a large error in the calculation of the maximum compressive strength. According to GB/T 8813-2008 Rigid Cellular Plastics-Determination of Compression Properties, a national standard of the People's Republic of China, if the yield point appears before the compressive strain reaches $10 \%$, the stress at the yield point is the compressive strength; if there is no yield point, the corresponding compressive stress at the compressive strain of $10 \%$ is defined as the compressive strength. Therefore, the compressive strength of PCS, CCS, and CFS is shown in Table 7. 


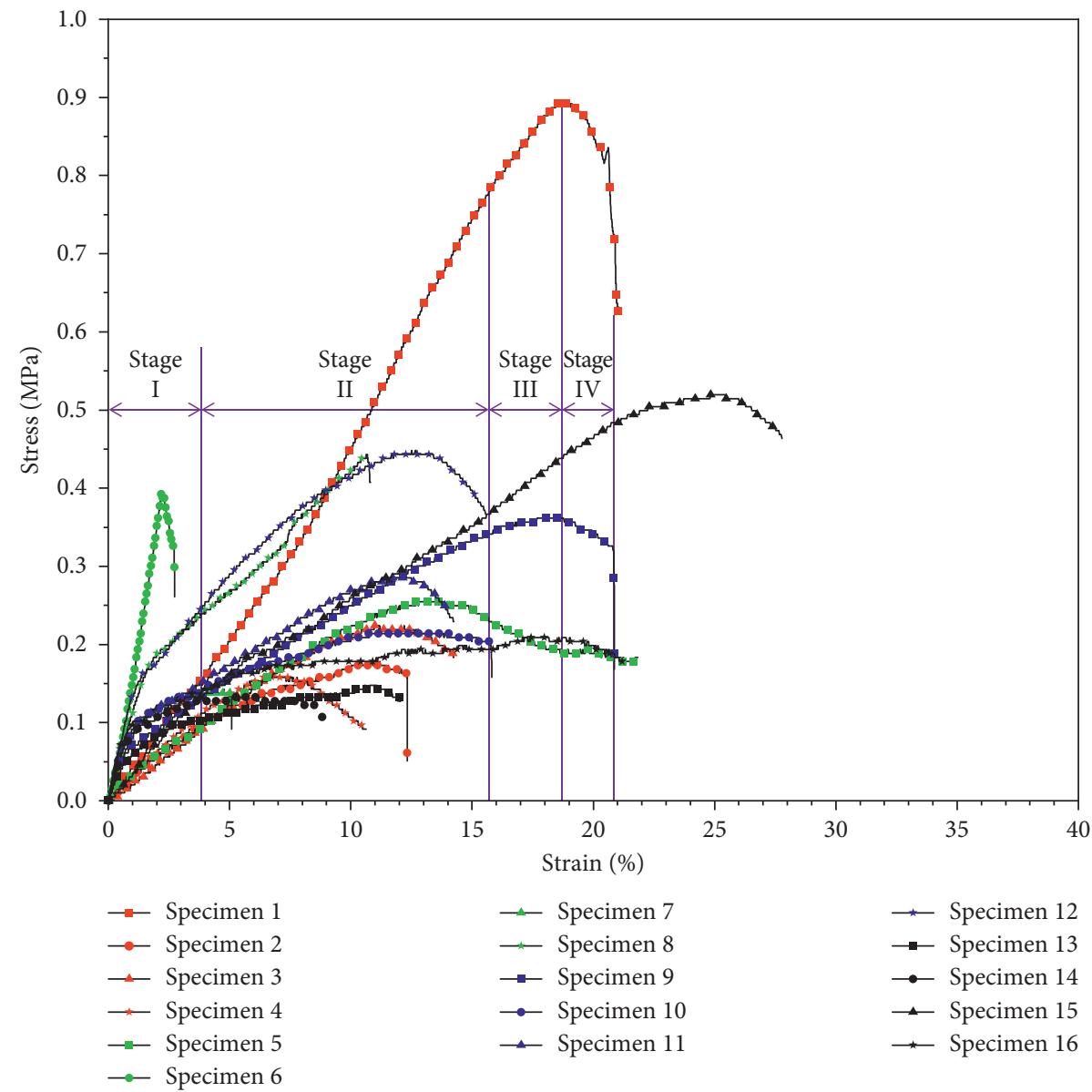

(a)

FIgURE 6: Continued. 


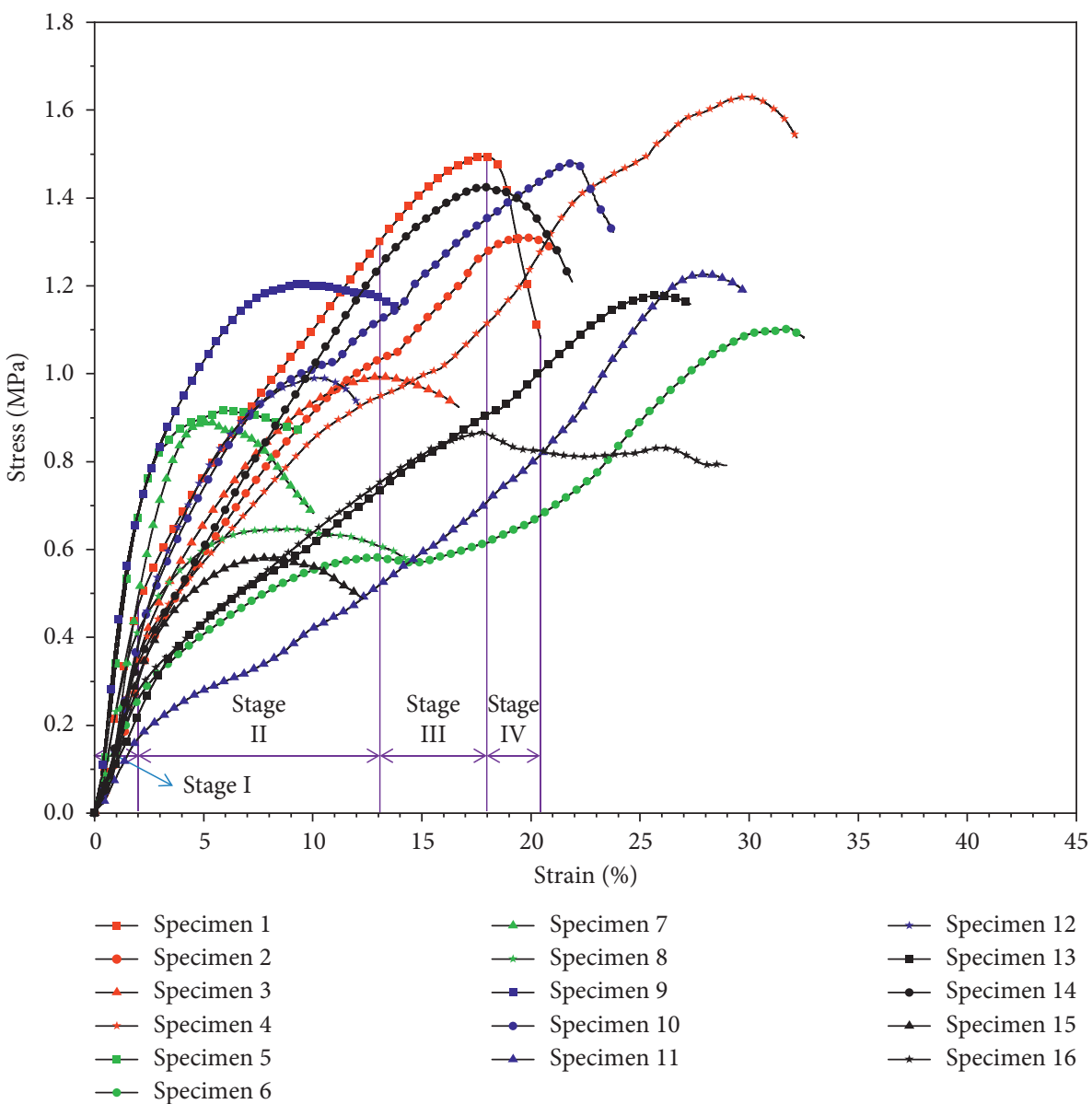

(b)

FIGURE 6: The stress-strain curves of specimens under uniaxial compression. (a) CCS and (b) CFS.
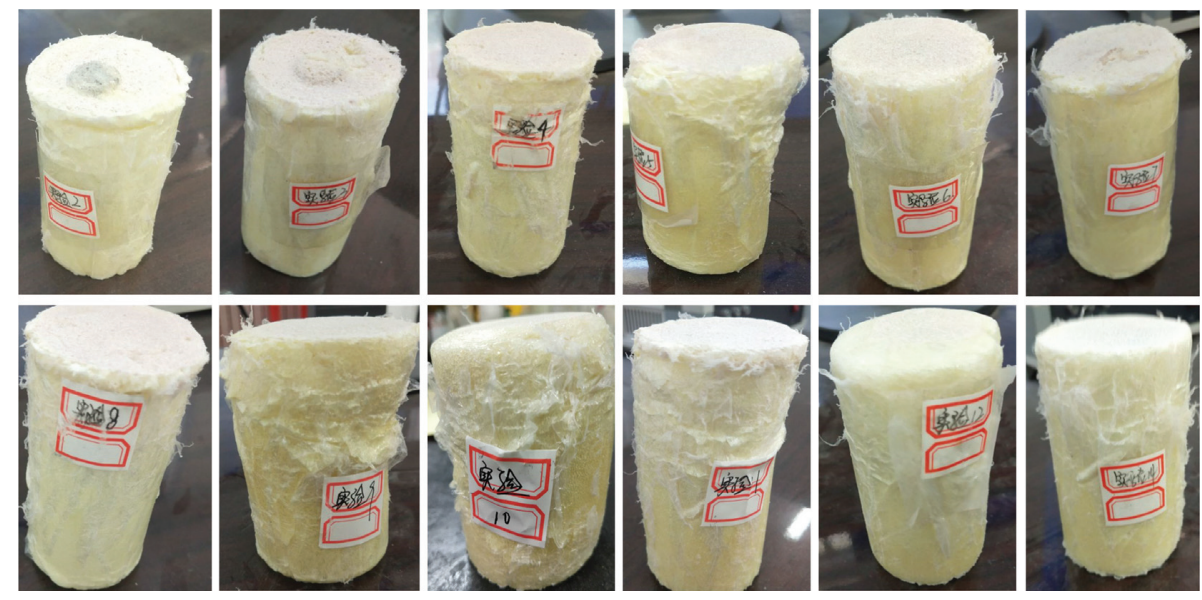

FIgURE 7: Plastic failure and deformation of PCS.

The compressive strength of CFS ranged from $1.16 \mathrm{MPa}$ to $8.45 \mathrm{MPa}$ at the strain of $10 \%$. The compressive strength of CFS ranged from $0.5 \mathrm{MPa}$ to $1.6 \mathrm{MPa}$, while that of CCS ranged from $0.1 \mathrm{MPa}$ to $0.9 \mathrm{MPa}$. The compressive strength of CFS as a whole was greater than that of CCS. Overall, the PU materials show a relatively good reinforcement effect on both coarse sand and fine sand. The results from Table 6 reveal that the compressive strength of PCS is much higher than that of CCS and CFS. On the one hand, the chain extension reaction was limited due to the presence of aggregate, resulting in the reduction of cohesion after solidified with sand; on the other hand, the mixed slurry was not evenly distributed in the sand. 
TABLE 7: Results of uniaxial compressive strength.

\begin{tabular}{|c|c|c|c|c|c|c|c|}
\hline \multirow[b]{2}{*}{ No. } & \multicolumn{4}{|c|}{ Factors } & \multicolumn{3}{|c|}{ Index } \\
\hline & & Polyether polyolsa $\mathrm{b}$ & Catalyst A33 & Surfactant BL-8468 & $\begin{array}{c}\text { UCS of PCS } \\
(\mathrm{MPa})\end{array}$ & UCS of CCS (MPa) & UCS of CFS (MPa) \\
\hline 1 & & $9: 11$ & 0.5 & 0.5 & 5.94 & 0.89 & 1.49 \\
\hline 2 & & $9: 11$ & 0.8 & 0.6 & 3.26 & 0.18 & 1.31 \\
\hline 3 & & $9: 11$ & 1.0 & 0.7 & 1.16 & 0.22 & 0.99 \\
\hline 4 & & $9: 11$ & 1.2 & 0.8 & 3.37 & 0.16 & 1.63 \\
\hline 5 & & $10: 10$ & 0.5 & 0.6 & 6.42 & 0.25 & 0.92 \\
\hline 6 & & $10: 10$ & 0.8 & 0.5 & 3.74 & 0.39 & 0.58 \\
\hline 7 & & $10: 10$ & 1.0 & 0.8 & 2.29 & 0.14 & 0.89 \\
\hline 8 & & $10: 10$ & 1.2 & 0.7 & 2.19 & 0.44 & 0.65 \\
\hline 9 & & $11: 9$ & 0.5 & 0.7 & 6.06 & 0.36 & 1.20 \\
\hline 10 & & $11: 9$ & 0.8 & 0.8 & 4.90 & 0.21 & 1.48 \\
\hline 11 & & $11: 9$ & 1.0 & 0.5 & 7.97 & 0.29 & 1.23 \\
\hline 12 & & $11: 9$ & 1.2 & 0.6 & 5.98 & 0.44 & 0.99 \\
\hline 13 & & $8: 12$ & 0.5 & 0.8 & 6.51 & 0.15 & 1.18 \\
\hline 14 & & $8: 12$ & 0.8 & 0.7 & 8.45 & 0.13 & 1.42 \\
\hline 15 & & $8: 12$ & 1.0 & 0.6 & 4.95 & 0.52 & 0.58 \\
\hline 16 & & $8: 12$ & 1.2 & 0.5 & 2.93 & 0.21 & 0.83 \\
\hline \multirow{5}{*}{$\begin{array}{l}\text { UCS } \\
\text { of PCS }\end{array}$} & $\overline{\mathrm{I}}_{j}$ & 3.433 & 6.232 & 5.145 & & & \\
\hline & ${\frac{J}{\mathrm{II}_{j}}}_{j}$ & 3.660 & 5.088 & 5.152 & & & \\
\hline & $\overline{\mathrm{III}}_{j}$ & 6.228 & 4.093 & 4.465 & & & \\
\hline & $\overrightarrow{\mathrm{IV}}_{j}$ & 5.710 & 3.618 & 4.268 & & & \\
\hline & $\bar{R}_{j}^{j}$ & 2.795 & 2.614 & 0.884 & & & \\
\hline \multirow{5}{*}{ UCS of CCS } & $\overline{\mathrm{I}}_{j}$ & 0.362 & 0.412 & 0.445 & & & \\
\hline & $\overline{\mathrm{II}}_{j}$ & 0.305 & 0.228 & 0.348 & & & \\
\hline & $\overline{\mathrm{III}}_{j}$ & 0.325 & 0.292 & 0.287 & & & \\
\hline & $\overline{\mathrm{IV}}_{j}$ & 0.253 & 0.313 & 0.165 & & & \\
\hline & $\bar{R}_{j}^{\prime}$ & 0.109 & 0.184 & 0.280 & & & \\
\hline \multirow{5}{*}{ UCS of CFS } & $\overline{\mathrm{I}}_{j}$ & 1.355 & 1.198 & 1.032 & & & \\
\hline & $\overline{\mathrm{II}}_{j}$ & 0.760 & 1.198 & 0.950 & & & \\
\hline & $\overline{\mathrm{III}}_{j}$ & 1.225 & 0.922 & 1.065 & & & \\
\hline & $\overline{\mathrm{IV}}_{j}$ & 1.002 & 1.025 & 1.295 & & & \\
\hline & $\bar{R}_{j}^{j}$ & 0.595 & 0.276 & 0.345 & & & \\
\hline
\end{tabular}

Variance analysis was carried out on the compressive strength of the prepared polyurethane grouting material. It can be seen from Table 8 that polyether polyols a:b was a significant factor for compressive strength. The order of the influence of the three factors on the compressive strength was polyether polyols $\mathrm{a}: \mathrm{b}>$ catalyst $>$ surfactant. The analysis of the results in Tables 7 and 8 showed that the conclusions of the two were consistent.

3.4.3. Macroscopic Failure Characteristics. As shown in Figure 7, it can be concluded that no cracking occurred when the PCS was compressed to the limit state, but the dilatation phenomenon was obvious accompanied by the decrease of specimen height. In the process of uniaxial compression, the bending occurred along the place with the weakest resistance because of the inhomogeneity, and no other obvious failure phenomenon appeared.

According to the experimental data and the failure characteristics of CCS and CFS in Figure 8, it can be seen that the PU filling materials distributed in the specimens filled the pores and consolidated with the loose sand as a whole.
Furthermore, from the failure mode of CCS and CFS in Figure 8 , we found that obvious cracks and fractures appeared in the specimens eventually. The opening and extending of fractures in CCS were larger than that in CFS; in addition, the former generally started from the bottom, while the latter generally fractured in the middle of specimens. The macroscopic phenomena suggest that the failure mode of CCS and CFS was brittle splitting fracture.

3.4.4. Microdeformation Characteristics after Compression. Goaf filling materials need to have a certain expansion ratio and good deformation and bearing capacity. Based on the above requirements, Samples 1, 5, 11, and 14 were selected for SEM analysis after comprehensive analysis of expansion ratio and compressive strength results, and macroperformance was explained through microstructure.

For specimen 1 in group I with an expansion ratio of 2.9 and compressive strength of $6.16 \mathrm{MPa}$ at a compressive strain of $14.14 \%$, the compression degree of cellular was small and no obvious folds appeared, as shown in Figure 4(a). For specimen 5 in group II with an expansion ratio of 2.0 and compressive 
TABLE 8: Results of variance analysis of compressive strength.

\begin{tabular}{|c|c|c|c|c|c|}
\hline Factors & Square of deviance & Degree of freedom & $F$ & $F \alpha=0.1$ & Significant level \\
\hline Polyether polyols $\mathrm{a}: \mathrm{b}$ & 24.113 & 3 & 1.692 & 2.810 & Significant \\
\hline Catalyst A33 & 16.105 & 3 & 1.130 & 2.810 & \\
\hline Surfactant BL-8468 & 2.527 & 3 & 0.177 & 2.810 & \\
\hline Error & 42.74 & & & & \\
\hline Sum & 85.485 & 9 & & & \\
\hline
\end{tabular}

strength of $7.36 \mathrm{MPa}$ at a compressive strain of $30.86 \%$, Figure 4(b) shows the cellular compression degree was larger, and more folds were observed on the cellular surface. For specimen 11 in group III with an expansion ratio of 2.1 and a compressive strength of $7.43 \mathrm{MPa}$ at a compressive strain of $33.14 \%$, it can be seen from Figure 4(c) that the cellular wall deformed and the cellular pores exposed. For specimen 14 in group IV with an expansion ratio of 2.1 and a compressive strength of $6.51 \mathrm{MPa}$ at a compressive strain of $9.21 \%$, Figure 4(d) shows that the flattening and stretching phenomenon of cellular wall had appeared. Taken together, the more the surfactants content was, the more uneven the cellular distribution was and the more serious the compression deformation was. The results show that specimens with a surfactant ratio of 0.5 perform well in microdeformation.

\section{Discussion}

4.1. Verification of Exothermic Property. Reaction of PAPI and $\mathrm{MDI}$ with polyether polyols produced carbamate, which was one of the main reactions. However, when $\mathrm{H}_{2} \mathrm{O}$ existed in component $\mathrm{B}$, PAPI and MDI reacted with $\mathrm{H}_{2} \mathrm{O}$ at first with the product of amines and the release of $\mathrm{CO}_{2}$ at the same time. After that, amines reacted with PAPI and MDI with the product of polyurea. The reaction process is as follows:

(1) Reaction of PAPI and MDI with polyether polyols:

$$
\mathrm{nOCN}-\mathrm{R}-\mathrm{NCO}+\mathrm{nHO}-\mathrm{R}^{\prime}-\mathrm{OH} \rightarrow-\left[\begin{array}{ccc}
\mathrm{H} & \mathrm{O} & \mathrm{H} \\
\| & \| & \multicolumn{1}{l}{} \\
\mathrm{O}-\mathrm{C}-\mathrm{N}-\mathrm{R}-\mathrm{N}-\mathrm{C}-\mathrm{O}-\mathrm{O}-\mathrm{R}^{\prime}-\mathrm{O}
\end{array}\right]_{\mathrm{n}}+\text { Heat }
$$

(2) Reaction of PAPI and MDI with $\mathrm{H}_{2} \mathrm{O}$ :

$$
2 \mathrm{nOCN}-\mathrm{R}-\mathrm{NCO}+\mathrm{nH}_{2} \mathrm{O} \rightarrow-\left[\begin{array}{ccc}
\mathrm{H} & \mathrm{O} & \mathrm{H} \\
\mathrm{I} & \| & 1 \\
\mathrm{R}-\mathrm{N}-\mathrm{C}-\mathrm{N}-\mathrm{R}
\end{array}\right]_{\mathrm{n}}+\mathrm{nCO}_{2} \uparrow+\text { Heat }
$$

A large amount of heat was generated in the above reaction process; as a result, the materials with a low flash point are prone to spontaneous combustion. Therefore, it is of great significance to reduce the maximum reaction temperature.

Considering the exothermic property, all the specimens meet the requirement that the maximum reaction temperature must be lower than $140^{\circ} \mathrm{C}$. However, the highest reaction temperature of Group I and Group III was lower than that of Group II and Group IV; that is to say, the formulas of specimens 1, 2, 3, and 4 and specimens 9, 10, 11, and 12 are ideal considering the exothermic property.

4.2. Effect Factors of Foaming and Mechanical Properties. Our results indicate that, in each group from Group I to Group IV, the higher the mass ratio of surfactants is, the greater the expansion ratio is. Surfactants reduced the surface tension of the PU materials and decreased the foaming density; as a result, the foaming rate increased and the expansion ratio decreased. Our findings on the effect factor of foaming property agree with those reported by Shi and Zhao who obtained that the surfactants had the largest $R$-value and the greatest influence on PU grouting materials through orthogonal test analysis [34]. Surfactants in the reaction stage contribute to the formation of microcellular, which can weaken diffusion in foaming initiation. In summary, we have identified that less surfactant is difficult to form cellulars or causes serious cellular coalescence, while more surfactants lead to the break and collapse of cellulars due to the thin cellular wall and weak skeleton.

From Table 6, it can be concluded that, in the uniaxial compression experiments of PCS and CFS, the range of polyether polyols a : $\mathrm{b}$ was the largest, which were 2.795 and 0.595 , respectively; that is, the mass ratio of polyether triols in polyether polyols had the greatest effect on compressive strength. The mechanical properties can be improved by increasing the proportion of polyether triols in polyether polyols. This is because the functionality changed after different proportions of polyether polyols mixed; the higher the functionality of polyether polyol was, the higher the hydroxyl value was, resulting in high density of crosslinking network formed by the reaction of polyether polyols with PAPI and MDI. However, the range of surfactants was the largest for CCS; that is, surfactant was the main factor affecting the mechanical property and has a negative effect on compressive strength. Our data are consistent with Liang et al. who suggested that increasing the content of 


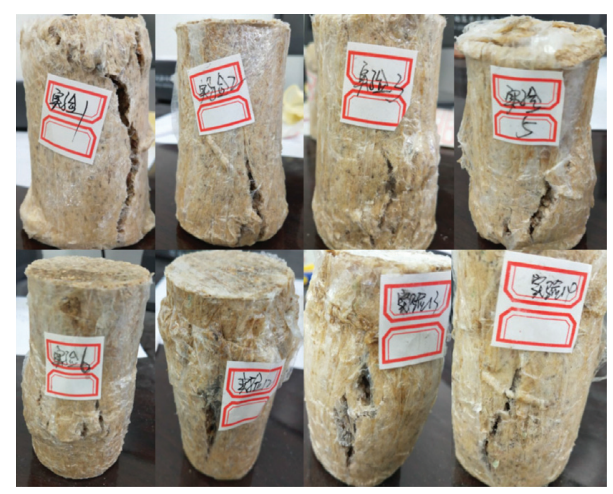

(a)

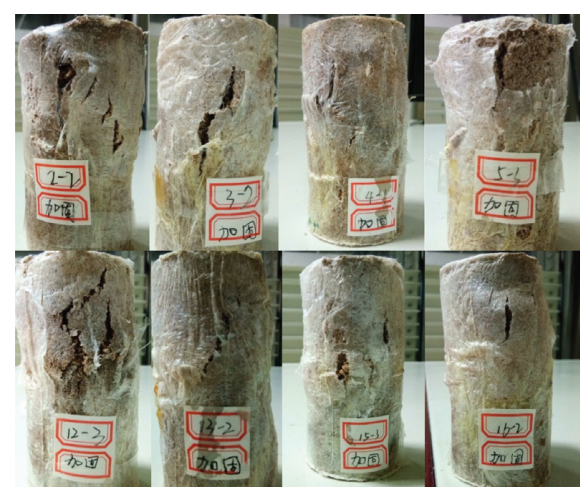

(b)

FIgURE 8: Splitting failure of specimens under uniaxial compression. (a) CCS and (b) CFS.

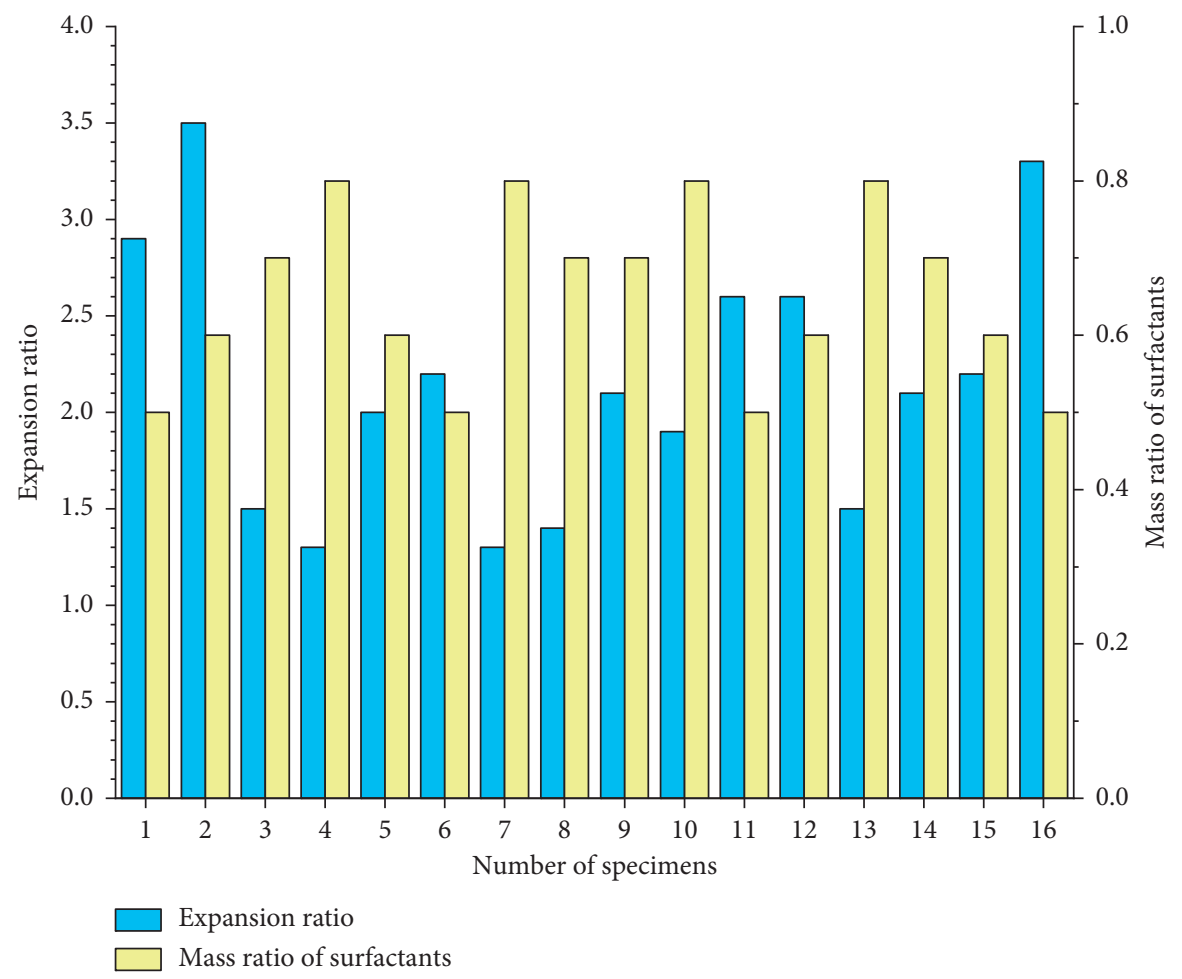

FIGURE 9: Relationship of surfactants with foaming property.

surfactants can improve the tensile strength in the proper range but has little effect on the compressive strength [35]. Zhang studied the effect of grouting amount and curing time on compressive strength [36]. The above factors were not taken into account in this experiment and should be further considered in future experiments.

\subsection{Formula Determination of PU Filling Materials for Goaf} Sealing Wall. According to the requirements of foaming performance, it is necessary to have a large expansion rate, but excessive expansion rate will seriously reduce the mechanical properties of the material [37]. Therefore, Figures 9 and 10 show that the mass ratio of surfactants should be balanced with expansion ratio and uniaxial compressive strength. These data suggest that the ideal expansion ratio ranges from 2.5 to 3.0 and suggest that specimens 1,11 , and 12 satisfied the requirements, and the corresponding expansion ratios were $2.9,2.6$, and 2.6, respectively.

Overall, our studies show that the pure chemical slurry as a filling material is superior to the combination of chemical slurry and sand in compressive strength and deformation performance. Based on the mechanical strength and deformation characteristics, the ideal formulas are specimens $6,9,11,13$, and 14 with compressive strength greater than $6.0 \mathrm{MPa}$ at a strain of $10 \%$. In summary, the formula corresponding to specimen 11 is the most suitable due to the maximum reaction temperature of $121.4^{\circ} \mathrm{C}$, the expansion ratio of 2.6, and the compressive strength of $7.97 \mathrm{MPa}$ at the strain of $10 \%$. Our results confirm that the optimal mass 


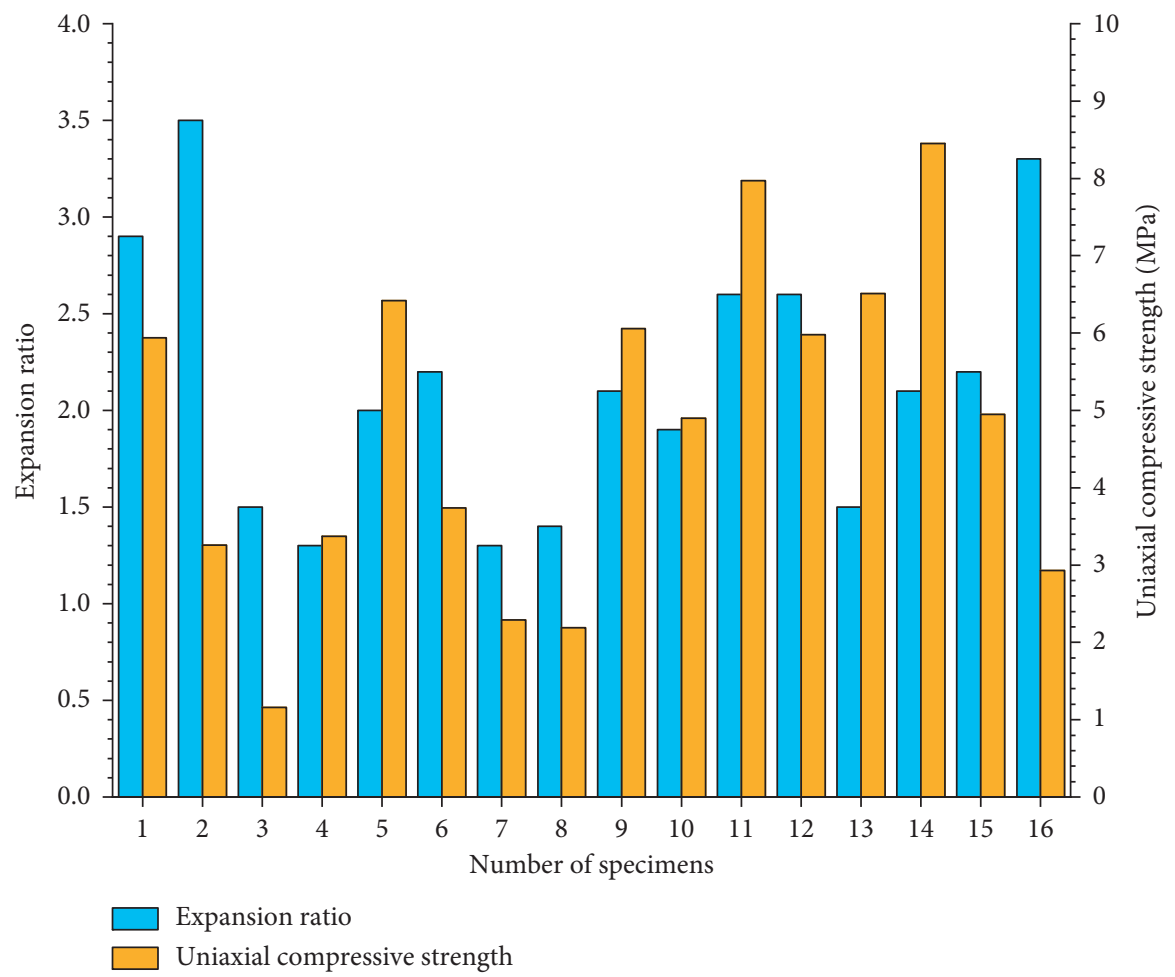

FIgURE 10: Relationship of expansion ratio with mechanical property.

ratio of polyether triols, polyether tetraols, catalysts, surfactants, chain extenders, and plasticizers is $11: 9: 1.0: 0.5$ : $1.2: 6$ in component B in this study.

Furthermore, PU filling materials for goaf sealing walls have the advantages of simple operation, convenient construction, and quick reaction, which are suitable for application under any conditions, especially suitable for high gas content, large mining stress, serious roadway deformation, and poor transportation conditions. Specifically, our findings suggest that the sealing wall consists of rigid brick walls on both sides and flexible filling body in the middle; the filling body generates large deformation rather than cracks or fractures under the action of mining stress so as to achieve the purpose of pressure relief. After that, when the filling body and the brick wall deform together, the mining stress is no longer obvious due to the pressure relief. Therefore, as a whole, the sealing wall can still play a role in preventing water and air leakage, and our results are consistent with those reported by Wei et al. [38]. More importantly, compared with traditional cement materials used in underground coal mine, polymer materials have excellent injectability, rapid reactivity, and strong diffusivity and can be used to deal with the leakage of water or air and improve mechanical strength that traditional materials cannot solve in a short time $[39,40]$.

4.4. Limitations of the Study. Although a lot of work has been done in this experiment, some deficiencies still need further improvement and optimization. Firstly, flame retardants and smoke suppressants should be considered and corresponding properties also need further test and characterization; secondly, the effect of chain extenders and plasticizers should be further carried out using the singlefactor index method; finally, our results lack data on the effect of different sand contents on mechanical property.

\section{Conclusions}

In this paper, the combination of PAPI and MDI as component A and polyether triols, polyether tetraols, catalysts, surfactants, chain extenders, and plasticizers as component B were prepared. Then, the expansion ratio, reaction temperature, compressive strength, and deformation characteristics were measured and the following conclusions were obtained:

(1) The dynamic acquisition system and thermocouple sensor were used to monitor the reaction temperature in real time. The maximum reaction temperature of specimens was lower than $140^{\circ} \mathrm{C}$, which conformed to the national standard.

(2) The expansion ratio ranged from 1.3 to 3.5 , and the surfactants had the greatest effect on foaming property. Moreover, these data suggest that the expansion ratio ranging from 2.5 to 3.0 satisfied the requirements of foaming and mechanical properties.

(3) The results confirm that the pure chemical slurry as a filling material is superior to the combination of chemical slurry and sand in compressive strength and deformation performance. The optimal mass ratio of polyether triols, polyether tetraols, catalysts, surfactants, chain extenders, and plasticizers is $11: 9$ : 1.0:0.51.2:6 in component B considering exothermic, foaming, and mechanical properties in this 
study. The PU materials with optimized formula can be used as a filling body for goaf sealing wall for preventing water and air leakage under mining stress that traditional materials cannot solve in a short time.

\section{Data Availability}

The experimental data used to support the findings of this study are available from the corresponding author upon request.

\section{Conflicts of Interest}

The authors declare that there are no conflicts of interest regarding the publication of this paper.

\section{Acknowledgments}

This research was funded by the China National Natural Science Foundation (nos. 41807211, 51904032, and 51874192), Open Fund of Mine Disaster Prevention and Control Key Laboratory of Ministry of Education (no. MDPC201920), and SDUST Research Fund (grant no. 2018TDJH102).

\section{References}

[1] K. Kogler, J. Hechenbichler, and P. Gabriel, "Injektionsmaßnahmen im Talsperrenbau," Geomechanics and Tunnelling, vol. 12, no. 2, pp. 129-140, 2019.

[2] D. Gabriel and J. Oh, "Permeation grouting for remediation of dam cores," Engineering Geology, vol. 233, pp. 63-75, 2018.

[3] D.-M. Zhang, Z.-K. Huang, R.-L. Wang, J.-Y. Yan, and J. Zhang, "Grouting-based treatment of tunnel settlement: practice in Shanghai," Tunnelling and Underground Space Technology, vol. 80, pp. 181-196, 2018.

[4] H. Strømsvik, "The significance of hydraulic jacking for grout consumption during high pressure pre-grouting in Norwegian tunneling," Tunnelling and Underground Space Technology, vol. 90, pp. 357-368, 2019.

[5] S. Saleh, N. Z. M. Yunus, K. Ahmad, and N. Ali, "Improving the strength of weak soil using polyurethane grouts: a review," Construction and Building Materials, vol. 202, pp. 738-752, 2019.

[6] A. Z. Elwakil and W. R. Azzam, "Soil improvement using grout walls," Alexandria Engineering Journal, vol. 55, no. 3, pp. 2741-2748, 2016.

[7] C. R. Qin, W. Lu, Z. L. He, G. Qi, J. Li, and X. Hu, "Effect of silane treatment on mechanical properties of polyurethane/ mesoscopic fly ash composites," Polymers, vol. 11, no. 4, p. 741, 2019.

[8] Q. Liu, F. Xiao, and Z. Y. Zhao, "Grouting knowledge discovery based on data mining," Tunnelling and Underground Space Technology, vol. 95, Article ID 103093, 2020.

[9] Y. Tai, H. Xia, X. Meng, and T. Kuang, "Failure mechanism of the large-section roadway under mined zones in the ultrathick coal seam and its control technology," Energy Science \& Engineering, vol. 8, no. 4, pp. 999-1014, 2020.

[10] J. Huang, J. Sun, R. Zhang et al., "Improvement of biodegradability of UV-curable adhesives modified by a novel polyurethane acrylate," Progress in Organic Coatings, vol. 95, pp. 20-25, 2016.
[11] G. W. Wu and D. M. Yu, "Preparation and characterization of a new low infrared-emissivity coating based on modified aluminum," Progress in Organic Coatings, vol. 76, no. 1, pp. 107-112, 2012.

[12] C. A. Anagnostopoulos and T. T. Papaliangas, "Experimental investigation of epoxy resin and sand mixes," Journal of Geotechnical and Geoenvironmental Engineering, vol. 138, no. 7, pp. 841-849, 2012.

[13] V. Besse, L. Le Pluart, W. D. Cook, T.-N. Pham, and P.-J. Madec, "Synthesis and polymerization kinetics of acrylamide phosphonic acids and esters as new dentine adhesives," Journal of Polymer Science Part A: Polymer Chemistry, vol. 51, no. 1, pp. 149-157, 2012.

[14] C. Heinzmann, U. Salz, N. Moszner, G. L. Fiore, and C. Weder, "Supramolecular cross-links in poly (alkyl methacrylate) copolymers and their impact on the mechanical and reversible adhesive properties," ACS Applied Materials \& Interfaces, vol. 7, no. 24, pp. 13395-13404, 2015.

[15] B. Jiang, K. Oh, S. Kim, and He, "Technical evaluation method for physical property changes due to environmental degradation of grout-injection repair materials for water-leakage cracks," Applied Sciences, vol. 9, no. 9, p. 1740, 2019.

[16] Y. L. Lu, M. Q. He, L. G. Wang, B. Ren, X. Sun, and K. Zhang, "In-situ visualization experiments on the microscopic process of particle filtration of cement grouts within a rock fracture," Tunnelling and Underground Space Technology, vol. 95, Article ID 103157, 2019.

[17] C. Zhang, B. Shuai, X. Zhang et al., "Polyurethane/red mud composites with flexibility, stretchability, and flame retardancy for grouting," Polymers, vol. 10, no. 8, p. 906, 2018.

[18] M. Cao, C. Wang, R. Xia et al., "Preparation and performance of the modified high-strength/high-modulus polyvinyl alcohol fiber/polyurethane grouting materials," Construction and Building Materials, vol. 168, pp. 482-489, 2018.

[19] X. Liu, J. Wang, and K. Huang, "Experimental study on dynamic water grouting of modified water-soluble polyurethane," KSCE Journal of Civil Engineering, vol. 23, no. 8, pp. 3897-3906, 2019.

[20] W. S. Li, F. U. A. Shaikh, and L. G. Wang, "Experimental study on shear property and rheological characteristic of superfine cement grouts with nano- $\mathrm{SiO}_{2}$ addition," Construction and Building Materials, vol. 228, Article ID 117046, 2019.

[21] X. Zhang, L. Qiao, X. Lu, L. Jiang, and T. Cao, "Preparation and properties of toluene-diisocyanate-trimer-modified epoxy resin," Polymers, vol. 11, no. 3, p. 416, 2019.

[22] F. Jorne and F. M. A. Henriques, "Evaluation of the grout injectability and types of resistance to grout flow," Construction and Building Materials, vol. 122, pp. 171-183, 2016.

[23] X. Y. Liu, H. Cheng, J. Lin, C. Rong, M. Li, and H. Xu, "Study of the mechanism of fracture grouting in deeply buried rock strata based on bingham fluid slurry," Advances in Civil Engineering, vol. 2019, Article ID 6943239, 10 pages, 2019.

[24] A. Mortazavi and A. Maadikhah, "An investigation of the effects of important grouting and rock parameters on the grouting process," Geomechanics and Geoengineering, vol. 11, no. 3, pp. 219-235, 2016.

[25] J. Funehag and J. Thorn, "Radial penetration of cementitious grout-laboratory verification of grout spread in a fracture model," Tunnelling and Underground Space Technology, vol. 72, pp. 228-232, 2017.

[26] W. Q. Mu, L. C. Li, T. H. Yang, and G. Yu, "Numerical investigation on a grouting mechanism with slurry-rock coupling and shear displacement in a single rough fracture," 
Bulletin of Engineering Geology and the Environment, vol. 78, no. 4, pp. 1-19, 2019.

[27] M. M. Hao, X. L. Li, and Y. H. Zhong, "Numerical simulation of polymer grout diffusion in a single frace," AIP Advances, vol. 8, no. 10, 2018.

[28] T. Zhao, Y. C. Li, and J. Wang, "The optimization of new-tyoe mine closed materials and its application in shihe mine," Metal Mine, pp. 367-370, 2009.

[29] Y. C. Huang, H. H. Song, and T. Y. Lin, "The construction technology and application of expansion filling fire sealing wall," China Mining Industry, vol. 23, no. 7, pp. 130-132, 2014.

[30] H. F. Liu and Z. H. Wang, "Technology of applying new material grouting to reinforce and block permanent closed wall," Mining Safety and Environmental Protection, vol. 40, no. 4, pp. 87-90, 2013.

[31] Z. Liu, "The preparation and properties of polyurethane materials for sealing and filling in coal mine," Hefei University of Technology, 2012.

[32] J. J. Cheng and W. Shen, "Development of inflaming retarding polyurethane stowing material for underground mine," Coal Mining, vol. 17, no. 6, pp. 14-16, 2012.

[33] Z. M. Luo, J. Deng, and Y. B. Yang, "Study on hydrogel material for sealing and filling in coalmine disaster zone," Journal of China University of Mining and Technology, vol. 6, pp. 748-751, 2007.

[34] B. Y. Shi and J. Y. Zhao, "Experimental study on preparation of polyurethane grouting water plugging material," Construction Safety, vol. 35, no. 5, pp. 78-80, 2020.

[35] H. Liang, L. Fan, and Y. Z. Li, "Study on influencing factors of strength of polyether polyurethane grouting materials," Journal of Wuhan University of Technology, vol. 44, pp. 172176, 2020.

[36] X. N. Zhang, Study on Enginering Properties of Polyurethane Grouting Materials and Strengthening Properties of Fine sand, Doctor, Taiyuan University of Technology, Taiyuan, China, 2019.

[37] D. A. Apostol, D. M. Constantinescu, and F. Stuparu, "Characterization and damage assessment of polyurethane foams subjected to compression testing," Materiale Plastice, vol. 53, no. 3, pp. 454-457, 2016.

[38] Y. Wei, F. Wang, and X. Gao, "Microstructure and fatigue performance of polyurethane grout materials under compression," Journal of Materials in Civil Engineering, vol. 29, no. 9, 2017.

[39] S. Gutiérrez-González, J. Gadea, and A. Rodríguez, "Lightweight plaster materials with enhanced thermal properties made with polyurethane foam wastes," Construction and Building Materials, vol. 28, no. 1, pp. 653-658, 2011.

[40] K. Liu, W. Liang, F. Ren, J. Ren, F. Wang, and H. Ding, "The study on compressive mechanical properties of rigid polyurethane grout materials with different densities," Construction and Building Materials, vol. 206, pp. 270-278, 2019. 